\title{
THE EXISTENCE OF EQUILIBRIUM ASSET PRICE UNDER DIVERSE INFORMATION*
}

\author{
R. Agus Sartono
}

We investigate the effects of diverse information on the price of risky assets in rational expectation model. The expected cash flows innovation is considered as private information where informed trader knows it. It is assumed that the high informed trader has smaller variance error regarding the cash flows innovation than the lowinformed trader and uninformed traders. We found that the cash flow innovation influences the demand of informed trader. The market depth is a linear function of the demand of uninformed trader and weighted average of total variance error of information. Our finding supports previous research done by Spiegel and Subrahmanyam (1992).

Our model shows that the more diverse the information, the higher the lambda coefficient which means the market becomes less liquid. The models consistent with Miller (1977) who found that the bigger the gap of private information is, the less liquid the market will be. If both informed traders have the same information they will demand the same amount of risky asset and it turns out to be similar as in the Kyle (1985) model.

Keywords: diverse information; market depth and informed traders

* I would like thank to Klaus Schredelseker and Matthias Bank for their guidance; many thanks to Dr. Dedi Rosadi, M.Sc, Gunardi, M.Sc and Abdurahman, M.Sc at the Department of Mathematics, Gadjah Mada University for their assistance, the participants of the doctoral seminar at the Institute of Finance and Banking, the University of Innsbruck, and two anonymous referees for their constructive comments. The remaining errors are my responsibility. 


\section{Introduction}

The theory of financial markets under homogeneous information has generated a rich body of predictions, extensively used in the financial industry. In contrast, the theory of capital markets under diverse information has not been used much to guide asset pricing and portfolio allocation decisions. The goal of the paper is to explore the existence of equilibrium asset price under diverse information. We consider the one period of Kyle $(1985,1989)$ and Admati and Pfleiderer $(1987,1988)$ model where there are two informed traders posses diverse information and uninformed trader in the market. In another paper, Sartono (2005) proved that optimum demand of informed trader is a linear function of the private information as measured by the difference between the realization value of risky asset and the current price. Assuming that the information cost is a function of investment size, he found that the information acquisition has an impact on the optimum demand of informed trader.

It is evident that markets for information, taking a variety of forms, are important elements in financial market. The questions are how does trading strategy depends on the precision of information and is there an equilibrium asset price under diverse information? Do informed traders be better off than low informed traders or even uninformed trader? We assume that expectations about future prices influence the decisions of the traders and hence the current price. Traders have rational expectations about the link between the current signals and the current price, as in Grossman and Stiglitz (1976, 1980) and Admati (1985). The setting assumption in our model is a kind of game of incomplete information. Informed traders have signal or private information about cash flows innovation and the value of risky asset is determined by the expected cash flow innovations. Several interesting papers have analyzed implication of asymmetric or diverse information on the asset price (Kyle 1985 and Verrecchia 1982). Verrecchia (1982) has feature that informed traders take equilibrium price as a given, even though they influence the information content of the price through their traders. In this model, risk aversion prevents prices from fully revealing the private information of the informed traders. When the informed traders observe strongly correlated signals, an increase in their number will intensifies competition between them and leading to an increase in market liquidity.

Kyle (1985) started developing the asset price under asymmetric information. He assumes there is one risk-neutral insider or informed trader, market makers, and noise traders. Kyle proved that insider, as an informed trader, makes a positive profit by exploiting his power monopoly optimally in a dynamic context, where noise trading provides camouflage, which cancels his trading from market makers. Gorton and Pennacchi (1993) extended 
the one-period Kyle model to a twoperiod model and focused on the behavior of uninformed traders in an attempt to minimize loss trading with informed traders. Grossman (1976) and Grossman and Stiglitz (1980) showed how the heterogeneous information of different traders can be reflected on the equilibrium price of security. Using two types of traders who are informed and uninformed, they demonstrated how the price system transmits information from informed to uninformed traders. Nevertheless, if the price system aggregates perfectly private information, then it eliminates the incentive for traders to collect information.

Extending the Kyle's model, Diamond and Verrecchia (1981, 1987), Jackson (1991), and Easley and O'Hara (2001) analyzed the equilibrium, price formation and the value of private information. He showed that if the price formation process is modeled explicitly and traders are not price takers, then it is possible to have equilibrium with fully revealing prices and costly information acquisition. Equilibrium in costly information acquisition is ex ante Pareto inefficient, since resources are lost in the acquisition of information. They proved that if the price formation is explicit and traders influence the prices, then it is possible to have fully revealing prices. Both informed and low informed trade is who observe diverse information or signals as well as uniformed trades behave strategically, taking into account the effect of their demands on the market clearing price. William (1977) introduced an alternative model in pricing capital assets under heterogeneous beliefs and risk-aversion. He proved that beta is no longer a complete measure of risk. Figlewski (1982) proved that information level or diver information affect investors' beliefs or expectations. Thus, different investors may acquire different information, process it in different ways and respond differently. In another study based on a computer simulation model, Schredelseker (1997) developed a model that indicates that information does have a negative value and does not support the empirical evidence that investors are willing to spend a lot of money to get better information in advance.

\section{Model Setup}

We would like to develop another one period model similar to KyleAdmati-Pfleiderer model where there are two informed traders who possess diverse information and liquidity or uninformed traders. The two risk neutral informed traders have diverse private information or signals about the cash flow innovation in the end period. The error of private information or signals, $\widetilde{\varepsilon}_{i}$ is independent and normally distributed with mean zero. ${ }^{1}$ The in-

\footnotetext{
${ }^{1}$ Greorg Nöldeke and T. Tröger (2001) strongly argued that the normality is not only sufficient but also a necessary condition for the existence of linear equilibrium in the Kyle model. Mark Bagnoli, S. Viswanathan and Craig Holden ( 2001) proved similar but less strong argument of normality assumption.
} 
formed traders trade strategically and submit a market order simultaneously and independently to the market maker, given their private signal to maximize their expected profit. Moreover, no trader is informed of the demand of any other informed traders prior to make his own decision. The demands of uninformed traders are normally distributed, $\tilde{u} \sim N\left(0, \sigma^{2}\right)$, and we are not able to learn anything from their demand. In our model, the high informed trader, $x_{h}$ is assumed to have better private information as indicated by higher precision or smaller error than the low informed trader, $\boldsymbol{x}_{\boldsymbol{r}}$. The subscripts " " and " $h$ " stand for the low and high informed respectively. The informed traders have access to diverse and independently distributed (d.i.d) private information. Informed traders know that uninformed traders have to trade due to the liquidity need or they trade based on noise as if it were thought as information. ${ }^{2}$

In the simple case of two informed traders, the high informed trader is assumed not fully determine the price, other wise, the low informed and uninformed traders would not willing to trade with him. In a one-period setting, the high and the low informed traders have private information about 'cash flow innovations' of end period as $\widetilde{\delta}_{1}+$ $\widetilde{\varepsilon}_{h}$ and $\widetilde{\delta}_{1}+\widetilde{\varepsilon}_{l}$ respectively prior submit the market order. We assume the liquidation value of asset as follows:

$$
V=\bar{v}+\tilde{\delta}_{i}
$$

where $V$ is know to all traders at the beginning of trading, and informed traders know, $\widetilde{\delta}$ the cash flow innovations random variable. The random variable $\widetilde{\varepsilon}_{h}, \ldots . . \varepsilon_{l}$ are diverse and independently distributed, having mean zero and variance of high informed and low informed traders are $\sigma_{\varepsilon_{h}}^{2}, \sigma_{\varepsilon_{l}}^{2}$ respectively. In our setting, the different part of the private signal is the variance, where the low informed trader is assumed to have higher variance than the high informed one. ${ }^{3}$

We assume that the variance of private signal is as $\sigma_{\varepsilon_{l}}^{2}=a \sigma_{\varepsilon_{h}}^{2}$ where $a>1$. All traders submit the market order to the market makers. The market makers provide better liquidity to the market and they know the total order flows but not part of it. As a competitive profession, market makers are prevented from making profit. They possibly lose from trading with

\footnotetext{
${ }^{2}$ Spiegel and Subrahmanyam (1992) develop a similar model to Kyle's (1985) model in which they use risk averse uninformed traders instead of risk neutral uninformed traders. In their model, uninformed trade based on the risk sharing purposes, and they are called as hedgers.

${ }^{3}$ Klaus Schredelseker and Mattias Bank have raised this idea. They show how to formulate the hypothesis in a simple way. The informed traders have signal as $\widetilde{\delta}_{l}=\widetilde{\delta}_{1}+\widetilde{\varepsilon}_{l}$ and $\widetilde{\delta}_{h}=\widetilde{\delta}_{1}+\widetilde{\varepsilon}_{h}$ for low and high informed traders respectively. The random variable $\widetilde{\varepsilon}_{h} \sim N\left(0, \sigma_{\varepsilon}^{2}\right) ; \widetilde{\varepsilon_{l}} \sim N\left(0, \sigma_{\varepsilon_{1}}^{2}\right)$ and $\widetilde{\delta}_{1} \sim$ $N\left(\delta_{1}, \sigma_{\delta_{1}}^{2}\right)$. The expected value of private information is equal to the cash flows innovation in the end period, $E\left(\tilde{\delta_{t}}\right)=E\left(\tilde{\delta_{t}}\right)=\delta_{1}$. Let's take the variance of private information of high and low informed traders, $\operatorname{Var}\left(\delta_{1}\right)=\operatorname{Var}\left(\delta_{1}\right)+\operatorname{Var}\left(\varepsilon_{l}\right)=\sigma_{\delta_{1}}^{2}+\sigma_{\varepsilon_{1}}^{2}$ and $\operatorname{Var}\left(\delta_{h}\right)=\operatorname{Var}\left(\delta_{1}\right)+\operatorname{Var}\left(\varepsilon_{h}\right)=\sigma_{\delta_{1}}^{2}+\sigma_{\varepsilon_{h}}^{2}$. We assume that $\operatorname{Var}\left(\delta_{l}\right)=a \operatorname{Var}\left(\delta_{h}\right)$, therefore, $\sigma_{\varepsilon_{1}}^{\sigma_{1}}=a \sigma^{2} \varepsilon_{h}$.
} 
informed traders but make profit from trading with uninformed traders. Following Admati and Pfleiderer (1988) approach, the market maker set the asset price as linear function of total order flow as follow:

$$
P[\tilde{y} \mid \Phi]=\bar{v}+\lambda(\tilde{y})
$$

where $\Phi=\left(\tilde{\delta}_{i}, \tilde{\delta}_{h}\right)$. In the equilibrium $E[V-P(\tilde{y}) \mid \tilde{\Phi}]=0$ condition must hold; other wise, there will be an opportunity to earn better return. Since the informed traders hold diverse private information, therefore, there must be kind of Nash equilibrium under incomplete information. The information of other informed traders does influence the decision of an informed trader. The low informed trader knows that he is trading against the high informed trader, and uninformed traders as well in the market.

\section{The Optimum Demand of Informed Traders}

The setting assumption is a kind of a strategic game of incomplete information; an informed trader holds the correct expectation about the other informed traders' behavior and acts rationally. In making decision, an informed trader has to take into account the expectation of other informed trader given the private information. Each informed trader has to move strategically, otherwise, he will not be able to benefit from having private informa- tion. The asset price is assumed to be partially revealing and so it provides incentive for information traders to acquire costly information, otherwise there would be no traders willing to spend a single euro for any information. The informed trader has diverse information just before submitting the order.

Lemma 1. Assumed that high informed and low informed traders have diverse information, the optimum demand of the high informed and the low informed traders are as follows:

$$
\beta_{h}=\left(\frac{1}{3 \lambda}\right)\left(\frac{\sigma_{\delta_{1}}^{2}}{\sigma_{\delta_{1}}^{2}+\sigma_{\varepsilon_{h}}^{2}}\right)
$$

and

$$
\beta_{1}=\left(\frac{1}{3 \lambda}\right)\left(\frac{\sigma_{\delta_{1}}^{2}}{\sigma_{\delta_{1}}^{2}+\sigma_{\varepsilon_{1}}^{2}}\right)
$$

Proof: We assume, the price is a linear function of total order flow as:

$$
\widetilde{P}[\tilde{y} \mid \Phi]=\bar{v}+\lambda(\tilde{y})
$$

We take a similar approach as in Admati and Pfleiderer (1988) and Spegel and Subrahmanyam (1992). The high informed trader maximizes his profit given his information and expected private information of the low informed trader. If the high informed trader conjecture that the market order of the low informed trader is $\beta_{1}\left(\widetilde{\delta}_{1}+\widetilde{\varepsilon}_{l}\right)$; the profit maximization of the high informed trader, $x_{h}$ is as Equation 3 . 
Gadjah Mada InternationalJournal of Business, September-December 2005, Vol. 7, No. 3

$$
\begin{aligned}
& \operatorname{Max}_{x_{h}} E\left\{x_{h}(V-P(\tilde{y})) \mid \tilde{y}, \widetilde{\delta}_{1}+\widetilde{\varepsilon}_{l}\right\}
\end{aligned}
$$

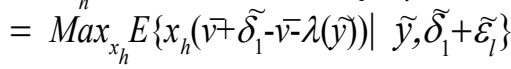

$$
\begin{aligned}
& =\operatorname{Max}_{x_{h}} E\left\{x _ { h } \left[\tilde{\delta_{l}}-\lambda\left(x_{h}+\beta_{l}\left(\tilde{\delta_{1}}+\widetilde{\varepsilon_{l}}\right)+\right.\right.\right. \\
& \left.u)] \mid \widetilde{\delta_{1}}+\widetilde{\varepsilon_{l}}\right\} \\
& =\operatorname{Max}_{x_{h}} \frac{x_{h} \sigma_{\delta_{1}}^{2}}{\sigma_{\delta_{1}}^{2}+\sigma_{\varepsilon_{l}}^{2}}\left(\widetilde{\delta}_{1}+\widetilde{\varepsilon}_{l}\right)-x_{h} \lambda\left(x_{h}+\right. \\
& \left.\beta_{l}\left(\widetilde{\delta}_{1}+\widetilde{\varepsilon}_{l}\right)\right)
\end{aligned}
$$

We assume $E[\tilde{u}]=0$ and random variable, $\widetilde{\varepsilon}_{h}, \widetilde{\varepsilon}_{l}$ are independently distributed therefore, the expectation of $\widetilde{\varepsilon}_{h} \widetilde{\varepsilon}_{l}$ is zero. If we take the first derivation with the respect of $x_{h}$ and equating to zero, we can solve for the optimum order for high informed trader as Equation 4 .

$$
\begin{aligned}
& 2 x_{h} \lambda=\frac{\sigma_{\delta_{1}}^{2}}{\sigma_{\delta_{1}}^{2}+\sigma_{\varepsilon_{l}}^{2}}\left(\widetilde{\delta}_{1}+\widetilde{\varepsilon}_{l}\right)- \\
& \lambda \beta_{1}\left(\widetilde{\delta}_{1}+\widetilde{\varepsilon}_{1}\right) \\
& x_{h}=\frac{1}{2 \lambda}\left(\widetilde{\delta_{1}}+\widetilde{\varepsilon}_{l}\right)\left(\frac{\sigma_{\delta_{l}}^{2}}{\sigma_{\delta_{1}}^{2}+\sigma_{\varepsilon_{l}}^{2}}-\lambda \beta_{l}\right)
\end{aligned}
$$

If we substitute the variance of low informed trader with the variance of high informed trader, $\sigma_{\varepsilon_{l}}^{2}=a \sigma_{\varepsilon_{h}}^{2}$ and $a>1$ we will see the impact of the private information to the optimum demand is as Equation 5.

$$
x_{h}=\frac{1}{2 \lambda}\left(\tilde{\delta}_{1}+\tilde{\varepsilon}_{l}\right)\left(\frac{\sigma_{\delta_{1}}^{2}}{\sigma_{\delta_{1}}^{2}+a \sigma_{\varepsilon_{h}}^{2}}-\lambda \beta_{l}\right)
$$

In the Nash equilibrium the $x_{h}$ must equal to $\beta_{l}\left(\tilde{\delta}_{1}+\widetilde{\varepsilon}_{l}\right)$ and we know that the Equation (4) represent the optimum demand of the high informed trader. We can rearrange, therefore, as follows:

$$
\begin{aligned}
\beta_{l}\left(\widetilde{\delta_{1}}+\widetilde{\varepsilon}_{l}\right) & =\frac{1}{2 \lambda}\left(\widetilde{\delta}_{1}+\widetilde{\varepsilon}_{1}\right)\left(\frac{\sigma_{\delta_{1}}^{2}}{\sigma_{\delta_{1}}^{2}+\sigma_{\varepsilon_{l}}^{2}}-\lambda \beta_{1}\right) \\
\beta_{l}+\frac{1}{2} \beta_{l} & =\frac{1}{2 \lambda}\left(\frac{\sigma_{\delta_{1}}^{2}}{\sigma_{\delta_{1}}^{2}+\sigma_{\varepsilon_{l}}^{2}}\right) \\
\beta_{l} & =\left(\frac{1}{3 \lambda}\right)\left(\frac{\sigma_{\delta_{1}}^{2}}{\sigma_{\delta_{1}}^{2}+\sigma_{\varepsilon_{l}}^{2}}\right)
\end{aligned}
$$

The low informed trader also wants to maximize his profit, but he is less aggressive than the high informed trader. The low informed trader knows that there is a trader who has better information than him, but there are liquidity or uninformed traders as well. The profit maximization from the low informed trader's point of view can be found using the similar approach, therefore the optimum demand of the low informed trader is as follow:

$$
\begin{aligned}
& \operatorname{Max}_{x_{I}} E\left\{x_{l}(V-\mathrm{P}(y)) \mid y, \tilde{\delta_{1}}+\widetilde{\varepsilon_{h}}\right\} \\
& =\operatorname{Max}_{x_{1}} E\left\{x_{l}\left(v^{-}+\tilde{\delta_{1}}-\bar{v}-\lambda(\tilde{y})\right) \mid \widetilde{y}, \widetilde{\delta}_{1}+\widetilde{\varepsilon}_{h}\right\} \\
& =\operatorname{Max}_{x_{I}} E\left\{x_{l}\left[\widetilde{\delta}_{1}-\lambda\left(x_{l}+\beta_{h}\left(\tilde{\delta}_{1}+\widetilde{\varepsilon}_{h}\right)-\widetilde{u}\right)\right]\right. \\
& \left.\mid \widetilde{\delta}_{1}+\widetilde{\varepsilon}_{h}\right\} \\
& =\operatorname{Max}_{x_{1}} \frac{x_{l} \sigma_{\delta_{1}}^{2}}{\sigma_{\delta_{1}}^{2}+\sigma_{\varepsilon_{h}}^{2}}\left(\tilde{\delta_{1}}+\tilde{\varepsilon_{h}}\right)-x_{l} \lambda\left(x_{l}+\beta_{h}\left(\tilde{\delta_{1}}+\tilde{\varepsilon_{h}}\right)\right.
\end{aligned}
$$

As we assume that $E[\tilde{u}]=0$ and the private information is diverse, the ex- 
pectation of $\widetilde{\varepsilon}_{h} \widetilde{\varepsilon}_{l}$ is zero. If we take the first derivation with the respect of and equating to zero, we can solve for the optimum order of the high informed trader as follows:

$$
\begin{gathered}
2 x_{1} \lambda=\frac{\sigma_{\delta_{1}}^{2}}{\sigma_{\delta_{1}}^{2}+\sigma_{\varepsilon_{h}}^{2}}\left(\tilde{\delta}_{1}+\tilde{\varepsilon}_{h}\right)-\lambda \beta_{h}\left(\tilde{\delta}_{1}+\tilde{\varepsilon}_{h}\right) \\
x_{l}=\frac{1}{2 \lambda}\left(\tilde{\delta}_{1}+\tilde{\varepsilon}_{h}\right)\left(\frac{\sigma_{\delta_{1}}^{2}}{\sigma_{\delta_{1}}^{2}+\sigma_{\varepsilon_{h}}^{2}}-\lambda \beta_{h}\right)
\end{gathered}
$$

If we substitute the variance of the low informed trader with the variance of the high informed trader, $\sigma_{s_{r}}^{1}=g \sigma_{x_{s}}^{1}$, and $a>1$ into Equation (8), we will see the impact of the private information to the optimum demand as follows:

$$
x_{1}=\frac{1}{2 \lambda}\left[\tilde{\sigma}_{1}+\tilde{s}_{s}\right)\left(\frac{\sigma_{s_{1}}^{2}}{\sigma_{s_{1}}^{2}+\frac{1}{2} \sigma_{s_{s}}^{2}}-\lambda \beta_{s}\right)
$$

The higher the coefficient ' $a$ ' is, the lower the information level and the smaller the demand of the low informed trader will be. If $a=1$ it means that both informed traders have the same information level and it leads to i.i.d information scenario, following Admati and Pfleiderer (1988) and Spiegel and Subrahmanyam (1992), in the Nash equilibrium the $x_{h}$ must equal to $\beta_{l}\left(\widetilde{\delta}_{1}+\widetilde{\varepsilon}_{l}\right)$, and $x_{l}$ must equal to $\beta_{h}\left(\widetilde{\delta}_{1}\right.$ $\left.+\widetilde{\varepsilon}_{h}\right)$, therefore we can solve the Equation (9) for beta as Equation 10.

$$
\begin{gathered}
\beta_{h}\left(\widetilde{\delta}_{1}+\widetilde{\varepsilon}_{1}\right)=\frac{1}{2 \lambda}\left(\widetilde{\delta}_{1}+\widetilde{\varepsilon}_{h}\right)\left(\frac{\sigma_{\delta_{1}}^{2}}{\sigma_{\delta_{1}}^{2}+\sigma_{\delta_{h}}^{2}}-\lambda \beta_{h}\right) \\
\beta_{h}+\frac{\lambda \beta_{h}}{2 \lambda}=\left(\frac{1}{2 \lambda}\right)\left(\frac{\sigma_{\delta_{1}}^{2}}{\sigma_{\delta_{1}}^{2}+\sigma_{\delta_{h}}^{2}}\right) \\
\beta_{h}=\left(\frac{1}{3 \lambda}\right)\left(\frac{\sigma_{\delta_{1}}^{2}}{\sigma_{\delta_{1}}^{2}+\sigma_{\delta_{h}}^{2}}\right)
\end{gathered}
$$

Equation (4) and (9) show the optimum demand of the high informed and low informed traders respectively. It is obvious that the optimum demand is a linear function of the volatility of cash flow innovations and increasing in the precession of private information as measured by the error variance private of information. The higher the precession of information means the smaller the error variance of information. In the Nash equilibrium, the optimum demand of the high informed trader, as presented in the Equation (10), is linear function of the variance of cash flow innovations. The smaller the error variance of private information, $\sigma_{\varepsilon_{h}}^{2}$ the higher the demand will be.

The similar plausible argument can be applied for the low informed trader. Equation (6) shows that the demand of low informed trader is less than the demand of high informed trader as indicated that $\sigma_{\varepsilon}^{2}=\sigma_{\varepsilon_{h}}^{2}$ and $a>1$. It is decreasing the function of error variance of private information. If then both informed traders have the same information, they will demand 
the same amount of risky asset. So, the higher the parameter " $a$ " the smaller the demand of low informed trader. It means that the lower the information level the smaller the demand will be; the demand of the low informed trader is a linear function of the volatility of cash flow innovations.

\section{Pricing Strategy}

Let us now characterize equilibrium price trading behavior in the model. Given the pricing rule in Equation (2), the demand of the high and low informed traders is a linear function of random variables and normally distributed. We assume that the demand of uninformed traders are also normally distributed and the expected cash flows innovation, $\widetilde{\delta}_{1}$, conditional on private information is linear. By solving the linear Equations (2), (6) and (10), we will find the lambda coefficient. The following proposition presents the solution for the lambda coefficient.

Preposition 1: Given the optimum demand of the high informed and the low informed trader, the market makers set the pricing strategy as follows:

$$
\lambda=\frac{\left(\beta_{h}+\beta_{l}\right) \sigma_{\delta_{l}}^{2}}{\left(\beta_{h}^{2}+\beta_{l}^{2}\right) \sigma_{\delta_{1}}^{2}+\beta_{h}^{2} \sigma_{\varepsilon_{h}}^{2}+\beta_{l}^{2} \sigma_{\varepsilon_{1}}^{2}+\sigma^{2}{ }_{u}}
$$

where $\quad \beta_{\mathrm{u}}=\left(\frac{1}{3 x}\right)\left(\frac{\sigma_{\vec{z}_{1}}^{2}}{\sigma_{\vec{v}_{1}}^{2}+\sigma_{\vec{z}_{\mathrm{n}}}^{2}}\right)$

and

$$
\beta_{1}=\left(\frac{1}{3 \lambda}\right)\left(\frac{\sigma_{\vec{a}_{1}}^{2}}{\sigma_{\vec{u}_{1}}^{2}+\sigma_{\vec{u}_{1}}^{2}}\right)
$$

Proof: Similar to previous analysis, we know that the market depth which is measured by the reciprocal of lambda, refers to the ability of the market to absorb quantity without having a large impact on price. The lambda, $\lambda$ is equal to the covariance of order flow with the signal. In our setting, the high informed trader has smaller error than the low informed trader. Following Kyle (1985) and Admati and Pfleiderer's (1988) approaches, if we substitute Equation (6) and (10) into the demand function then we can solve for the lambda as follows:

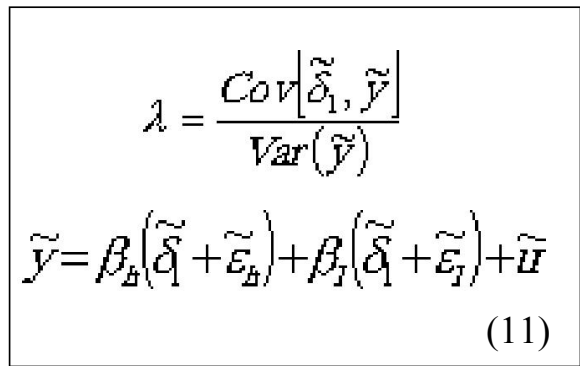

To find out the covariance between the total order flows and cash flow innovations, $\widetilde{\delta}$, the equation of total order flow can be rearranged as follows.

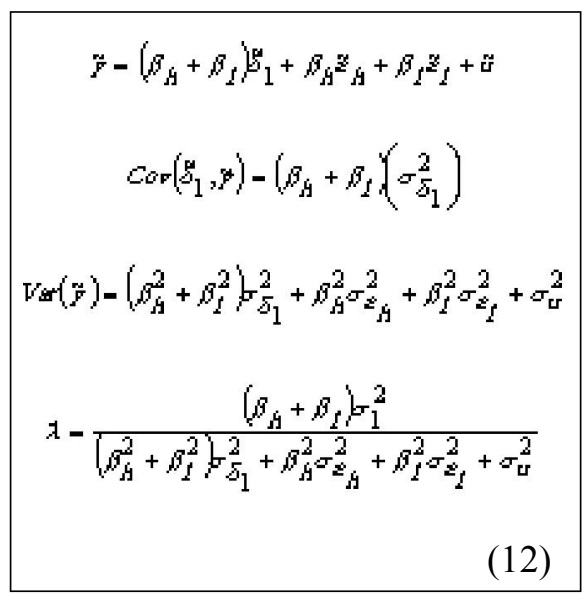


Sartono-The Existence ofEquilibrium AssetPrice under Diverse Information

Equation (12) shows that the market depth is a linear function of the volatility of cash flow innovations. The higher the volatility of cash flows innovations the bigger the market depth. In the simple case with only two informed traders, lambda is decreasing in the variance of uninformed trader and total variance of information error. The smaller the variance of information error, it means the better the private information and the bigger the lambda will be. The finding is similar to Admati and Pfleiderer (1988). However, if we have $n$ informed traders with diverse independently distributed information, it would be complicated and difficult to find a single-close form solution because private information has impact on the optimum demand. It is an interesting issue for further research.

\section{Computer Simulation}

In the previous part we have developed the mathematical model to capture the impact of diverse information on asset prices. To test whether the mathematical model is valid, we conduct a computer simulation. The computer simulation is considered as the easiest way to solve complex models since we can simulate a model as many as we need. Working with one period, we assume there are only two informed traders, uninformed traders and market maker. The high and low informed traders have private information about the cash flow innovation of the end period as $\widetilde{\delta}_{1}+\widetilde{\varepsilon}_{h}$ and $\tilde{\delta}_{1}+\widetilde{\varepsilon}_{l}$ respectively.
The cash flow innovations are assumed to benormally distributed, $\widetilde{\delta} \sim N\left(\delta_{1}, \sigma_{\delta_{l}}^{2}\right)$. The error variance of private information is $a \sigma_{\varepsilon_{h}}^{2}=\sigma_{\varepsilon_{1}}^{2}$ where $a>1$, it means that the low informed trader has a higher error variance than the high informed one. The demand of uninformed trader is normally distributed, $\tilde{u} \sim N\left(0, \sigma_{u}^{2}\right)$. The market maker sets the price as a linear function of total order flow to clear the market. In our simulation, we design the error variance of high informed trader in the range of $0.03-0.50$. The coefficient $a$ is made within the range of $1.10-$ 6.50 ; the volatility of cash flow innovations were controlled within the range of $0.10-0.90$. The volatility of uninformed traders were designed within the range of $0.10-0.90$.

Based on the optimization model, we generate the necessary random variables and find the optimum demand of both the high informed and low informed trader. Our intention of having a computer simulation is to see whether our mathematical models are quite justifiable. We compare the results from the mathematical model and from the sample. A plausible model should be able to generate result with only small deviation compared to the simulation results. The computer simulation is conducted based on the second model where the informed traders have diverse information. We do not simulate the first model because informed trader will demand equal amount of the risky asset when they have identical and independently distributed (i.i.d) information. 
Gadjah Mada International Journal of Business, September-December 2005, Vol. 7, No.3

\section{The Simulation Procedure and Results}

We conduct simulations up to 1,000 times and in each case we use 1,000 transaction with the initial asset price, $p_{0}=10$. The numbers of simulations, transactions and initial price were chosen arbitrary. Wemake several scenarios by controlling different random variables. For example, the coefficient of variance error of information, $a$ is designed to increase by different fractions and we recorded nine different results. Having the results we are able to create a graph showing the beta of the low informed trader, beta of the high informed trader and a lambda coefficient. The lambda refers to how the market maker learns about the cash flows innovation that determined the asset price of the risky asset from the order flows. In another scenario, we assume that the variance error of the high informed trader, the variance of the uninformed trader and $a$ are increasing. The increasing error variance of informed trader and the coefficient of error variance of information, means that the error variance of the low informed trader increase as well since $\sigma_{\varepsilon_{r}}^{2}=a \sigma_{\varepsilon_{\mathrm{o}}}^{2}$ We expect that having different graphs of informed traders' demand and the lambda enable us to draw further conclusions from our research.
In general, our computer simulations provide plausible results as it is indicated by a very small difference between the results based on the equation and based on the simulation. We simulate the model into nine scenario. In our first scenario, we assume that the coefficient of variance error of information increases and the variance error of the high informed trader, $\sigma_{x_{\boldsymbol{k}}}^{2}$ decreases. Panel A-1 shows that tne demand of low informed trader decreases in the beginning and increases thereafter. ${ }^{4}$ The decreasing demand reaches the minimum level when the variance error of low informed trader and informed trader are the same. Meanwhile the demand of the high informed trader increases at an increasing rate. It is due to the fact that he has better private information then the low informed traders. As a result the high informed trader enjoys the advantage of having better private information.

As we know that lambda measures how the market makers learn about the cash flows innovation that affect the asset price from the order flows. The market depth is measure by the reciprocal of lambda coefficient, refers to the ability of the market to absorb quantity without having a large impact on prices. The smaller the lambda is the more liquid the market. The lambda increases at an increasing

\footnotetext{
${ }^{4}$ The vertical axis of the graph indicates the demand of the high and low informed trader, and the lambda. The horizontal axis represents the nine different simulations with the respect to the different variables. For example, in Panel A-1, the error variance of high informed trader decreases and the private information gap increases.
} 
rates, it means that the reciprocal of lambda as a measure of market depth decreases. Increasing the lambda indicates that the change of order flow has a greater impact on the price and the market liquidity decrease.

It is plausible result because in our first scenario as it is indicated in Panel A-1, Panel A-2 and Panel A-3, the error variance of private information of high informed trader getting smaller while the volatility of cash flow innovation increases. At the same time the error variance of low informed trader rises, the high informed trader, therefore, become a kind of information monopolist. Another two similar scenarios can be seen in the Panel A-2 and Panel A-3, where the high informed trader enjoys the benefit of having private information. Panel A-2 shows another scenario when the volatility of uninformed trader and the coefficient of variance error increase. The decreasing error variance of the private information of high informed trader means also smaller the error variance of low informed trader. Therefore, the demand of both informed traders are increasing.

Now, let us take a look on the Panel A-3, the demand of high informed trader is a linear function of the quality of private information, especially when the volatility of cash flow innovation, $\sigma_{s_{1}}^{2}$ increases. This result supports our hypothesis that the smaller the variance error is, the bigger the advantage of having private information. Meanwhile the demand of the low informed trader decreases to its lowest level and increases subsequently.

We conduct another simulation by changing the combination of random variables. Panel B-1 shows that when the volatility of cash flow innovation and the coefficient variation error of private information increase, it means the variance error of the low informed trader increases as well, the demand of informed traders increase at a decreasing rate. The demand of the high informed trader, however, increases at a higher rate than the demand of low informed trader. It might be due to the fact that the low informed trader realizes that his information is getting less accurate. The high informed trader gains from having better private information.

Panel B-2 shows another scenario similar to the scenario in Panel B-1 but the volatility of the uninformed trader decreases. It indicates that the demand of the low informed trader increases at a decreasing rate. It is because the low informed trader faces a bigger disadvantage relative to the high informed trader. When the volatility of uninformed traders is constant and it provides an opportunity for low informed to take advantage of having private information. In all three cases, as in the Panel B-1, Panel B-2, and Panel B-3, the lambda increases, therefore the reciprocal lambda decreases. The market depth decreases at a decreasing rate and as a result, the market liquidity decreases as well. Similar to the first scenario in Panel A, the change in order flows has an impact on the price 
Gadjah Mada InternationalJournal of Business, September-December 2005, Vol. 7, No.3

Panel A-1

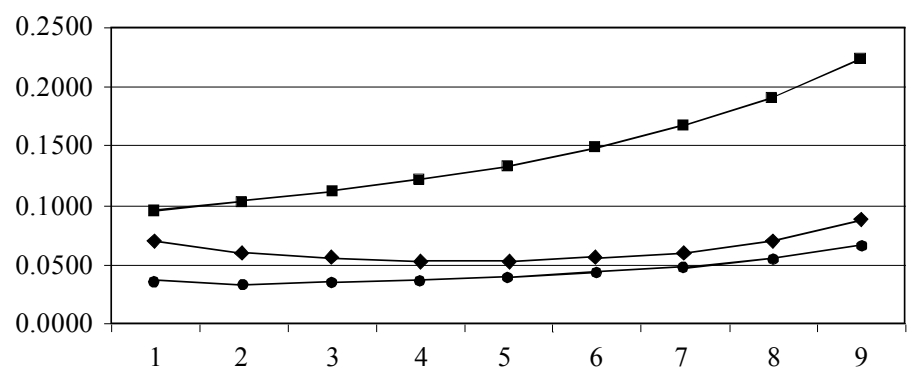

Panel A-2

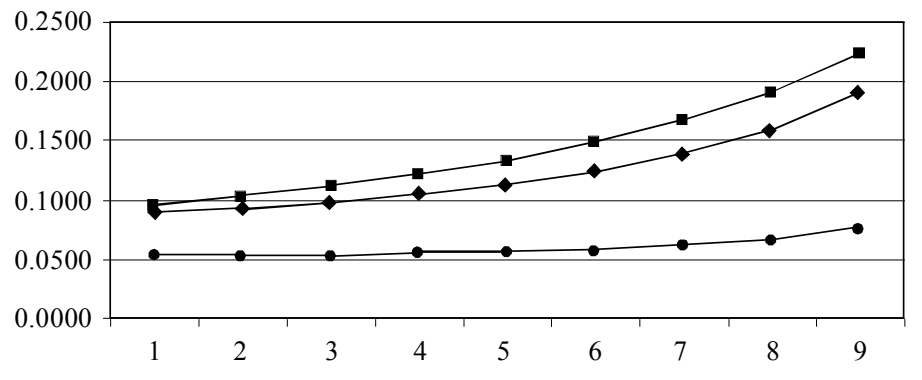

Panel A-3

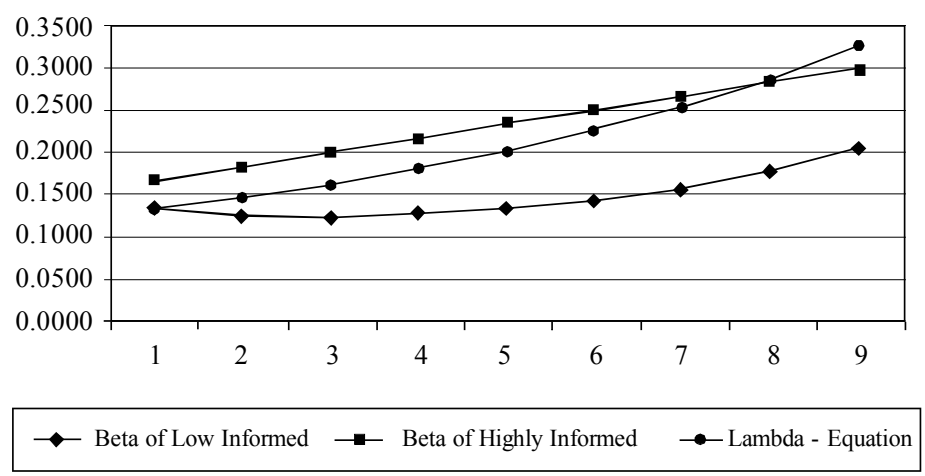

Panel A-1

$\sigma_{\varepsilon_{h}}^{2}$ Decreases and $a$ increases

Panel A-2

$\sigma_{\varepsilon_{h}}^{2}$ Decreases and $\sigma_{u}^{2}, a$ increases

Panel A-3

$\sigma_{\delta_{I}}^{2}, a$ Increase and $\sigma_{s h}^{2}$ decreases 
Sartono-The Existence ofEquilibrium AssetPrice under Diverse Information

Panel B-1

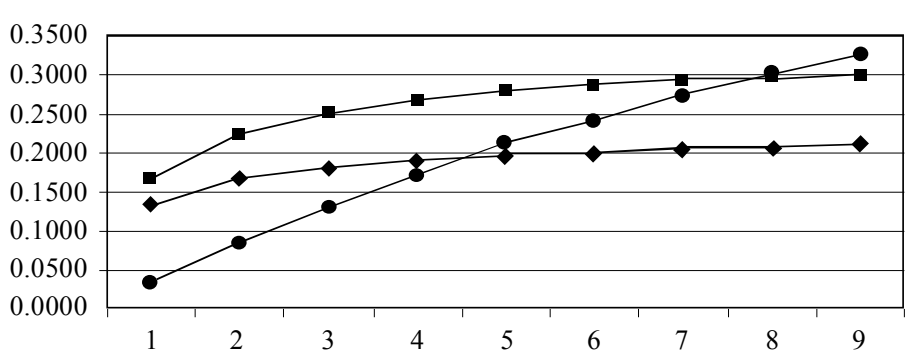

Panel B-2

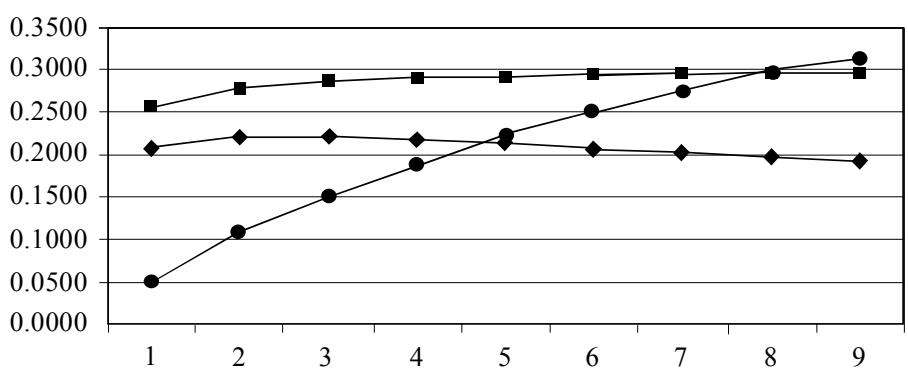

Panel B-3

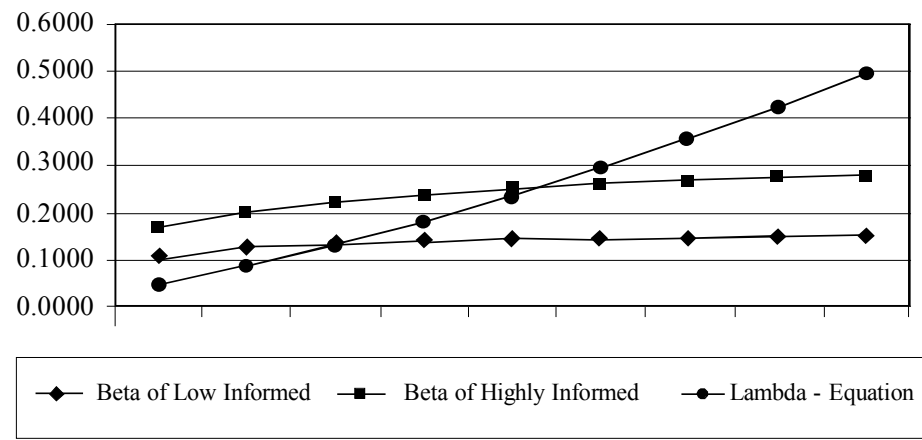

Panel B-1

$\sigma_{\delta_{1}}^{2}, a$ Increase

Panel B-2

$\sigma_{\delta_{l}}^{2}, a$ Increase and $\sigma_{u}^{2}$ decreases

Panel B-3

$\sigma_{\varepsilon_{h}}^{2}, \sigma_{\delta_{l}}^{2} a$ Increase 
Gadjah Mada InternationalJournal of Business, September-December 2005, Vol. 7, No.3

of risky asset. The market makers might learn when the volatility of cash flow innovation and the information gap between high informed and low informed traders become bigger, the order flow is mostly come from the high informed trader.

Now, let us take a look to the third scenario of our simulation. Panel C-1 shows that when the volatility of the uninformed trader, variance error of high and low informed traders rise, the demand of both informed traders decrease. The demand of the low informed trader decreases at a higher rate compared to the demand of the high informed trader. It might be due to the fact that both informed traders face bigger uncertainty, the noise increases and price becomes even less efficient. But the demand decreasing rate of the high informed trader is smaller than the one of the low informed trader. It means that the high informed trader is able to extract the advantage of having better private information than the low informed trader. Panel C-2 shows when the volatility of cash flow innovation, the error variance of private information and the volatility of uninformed traders increase, the demand of both informed traders decrease. It is because the informed traders have less precise private information.

Panel C-3 indicates similar results, when the error variance of the low informed trader and the volatility of uninformed traders increase, the decrease in the volatility of cash flow innovation do not change much the demand of informed traders. From all Panel C-1, Panel C-2 and PanelC-3 we find some thing in common that the demand of informed traders decrease due to the increasing variance error of private information and the volatility of uninformed traders. When the price becomes noise or less efficient, the low informed trader is not able to gain from his private information as well and the demand of informed trader decreases. The lambda of the third scenario is decreasing as well; as a result, the reciprocal lambda increases.

It is in line with the pattern of the demand of informed traders. The decreasing lambda means the market liquidity increase as measured by the reciprocal lambda. We are not able to find plausible arguments, however, why the market liquidity increases while the demand of informed traders decrease. We expect that the higher the liquidity of the market, the higher the demand of risky asset and when the market is liquid, the change in demand has small effect on the price of the risky asset.

We argue that the market liquidity increase as a result of decreasing demand of both high informed and low informed traders. The simulation results indicate that the market liquidity is inversely related to the demand of informed traders. The changes demand of informed traders has an impact on the price of the risky asset. Based on our nine scenarios, we are able to draw some general conclusions on the impact of random variable to the demand of informed traders. If the volatility of 
Sartono-The Existence ofEquilibrium AssetPrice under Diverse Information

Panel C-1

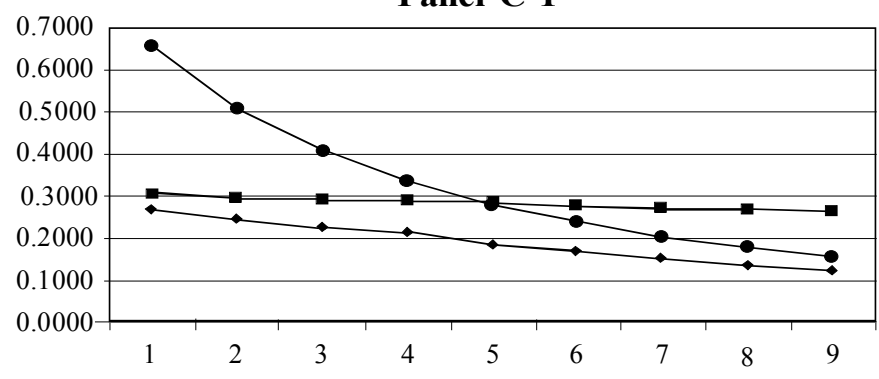

Panel C-2

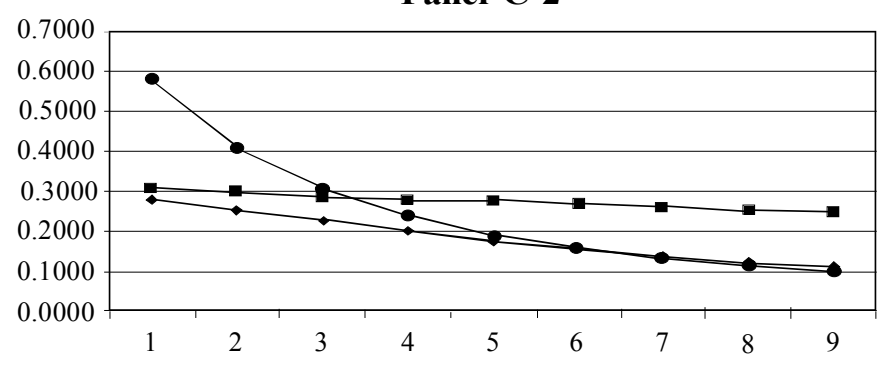

Panel C-3

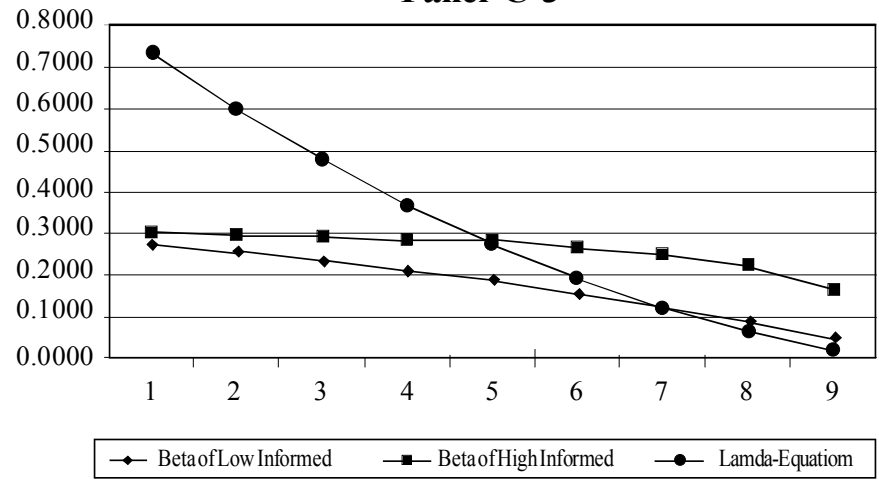

Panel C-1

$\sigma_{\varepsilon_{h}}^{2}, \sigma_{u}^{2}, a$ Increase

Panel C-2

$\sigma_{\varepsilon_{h}}^{2}, \sigma_{\delta_{l}}^{2}, \sigma_{u}^{2}, a$ Increase

Panel C-3

$\sigma_{\delta_{1}}^{2}$ Decrease and $\sigma_{u}^{2}, a$ Increase 
cash flow innovations and the variance errors of the low informed trader increase, the demand of informed traders increase at a decreasing rate. The volatility of cash flow innovation does influence the demand of informed traders and the volatility of uninformed trader does not affect the demand of high informed trader.

\section{Limitations and Advantages}

We simplified the Admati and Pfleiderer (1988) model and take a similar approach in Spiegel and Subrahmanyam (1992) model. We assume only two informed traders and the high informed trader's demand is conditional upon the private information of low informed trader. A low informed trader conjectures the demand of the high informed trader; and this is a kind of a game under incomplete information. So they have to take into account their private information. The problem is when we have more than two informed traders, we may find it is difficult and complex to solve in a single closed form solution because each informed trader has to forecast all the other informed traders' demand. This is due to each informed trader has to forecast the other informed traders' private information. We found that when the demand of informed traders increases, the market liquidity decreases. It means that the demand changes affect the asset price. Our result is consistent with Miller (1977), when the gap of private information between high and low in- formed trader increases, the market liquidity decreases.

In addition, unlike Spiegel and Subrahmanyam (1992) who assume that the uninformed traders are risk averse, we assume that the uninformed traders are exogenous and risk neutral. The assumption is still debatable. Some researcher may think that it is irrational and the irrational people must get out of the market. We argue that it is rational, because in the real world, a trader does not know whether he is better informed than the others traders or not. Regardless the limitation of this study, there is an advantage working with a simple model. We expect that our results will contribute to the issue of asymmetric information and asset pricing for $n$ number of traders.

\section{Conclusion}

In this research we examine the impact of diverse information on the asset price. We simplified the Admati and Pfleiderer (1988) model by using two informed traders. The informed traders have diverse private information about cash flows innovation and uninformed traders do not have private information. We found that the optimum demand of high informed trader is higher than the optimum demand of low informed trader given other factor constant. The market depth is a linear function of the demand of uninformed trader and weighted average of total variance error of information. Our findings support previous research done by Spiegel and 
Subrahmanyam (1992). If both informed traders have same information they will demand the same amount of risky asset and it turn out to be similar as in Kyle (1985) model.

Our model shows that the more diverse the information, the higher the lambda coefficient, which means the market become less liquid. The model is consistent with Miller (1977) who found that the smaller the gap of private information, the more liquid the market is. The model shows when the error variance of private information of high and low informed traders, volatility of uninformed traders, and volatility of cash flow innovation increase, the market depth as well as the market liquidity increase. This is due to the fact that prices become less efficient and the greater the value of private information. In summary, the price of the risky asset is a linear function of the volatility of cash flow innovations, and the precision of private information which is measured by the reciprocal of the error variance. Our findings may justify the argument that the higher the volatility of cash flow innovations, the bigger the adverse selection risk and therefore, the lower the price of the risky asset.

\section{Recommendation}

Our research opens some question for further investigation. First we do not model the information cost as a linear function of investment size. We assume that the high informed trader will continuously collect the information up to the marginal cost equal to the marginal benefit of having additional information. Second, we only work with two informed traders who have diverse information. Our computer simulation shows that the higher the information diversity or the gap between high and low informed trader increase, the demand of both informed traders decrease. It does not mean that low informed traders who have less accurate private information will demand fewer risky assets. The uninformed traders need to be endogenous and not necessary assumed to be risk neutral. Those issues are open for further research and need to be tested empiricallly.

\section{References}

Admati, R. A. 1985. A noisy rational expectation equilibrium for multi asset securities markets. Econometrica 53: 629-657.

Admati, R. A., and P. Pfleiderer. 1987. The value of Information in speculative trading. Research paper. Stanford University

Admati, R. A., and P. Pfleiderer. 1988. A theory of intraday patterns: Volume and price variability. Review of Financial Studies 1: 3-40.

Bagnoli, M., S. Viswanathan and C. Holden. 2001. On the existence of linear equilibria in models of market making. Mathematical Finance 11: 1-31. 
Gadjah Mada InternationalJournal of Business, September-December 2005, Vol. 7, No. 3

Diamond, W. D., and R. E. Verrecchia. 1987. Constraints on short selling and asset price adjustment to private information. Journal of Financial Economics 18: 227-311.

1981. Information aggregation in a noisy rational expectation economy. Journal of Financial Economics 9: 221-235.

Easley, D., and M. O’Hara. 2001. Information and cost of capital. Working Paper. Cornell University, USA.

Easley, D., S. Hvidkjare, and M. O'Hara. 2002. Is information risk a determinant of asset return? Journal of Finance 57: 2185-2221.

Fama, F. E. 1970. Efficient capital market: A review of theoryand empirical work. Journal of Finance 25: 383-417.

. 1991. Efficient capital market: II. Journal of Finance 46: 1575-1617.

Figlewski, S. 1982. Information diversity and market behavior. Journal of Finance 37: 87102

Foster, F. D., and S. Viswanathan. 1993. The effect of public information and competition on trading volume and price volatility. Review of Financial Studies 6: 23-56.

Grossman, J. S. 1976. On the efficiency of competitive stock markets where traders have diverse Information. Journal of Finance 31: 573-585.

1978. Further results on the informational efficiency of competitive stock markets. Journal of Economic Theory 18: 81-101.

Grossman, J. S., and J. E. Stiglitz. 1976. Information and competitive price system. American Economic Review 66: 256-253.

. 1980. On the impossibility of informationally efficient markets. American Economic Review 70: 393-408.

Holden, W. C., and A. Subrahmanyam. 1992. Long lived private information and imperfect competition. Journal of Finance 47: 247-270

Jackson, O. M. 1991. Equilibrium, price formation and the value of private information. Review of Financial Studies 4: 1-16.

Jackson O, M., and J. Peck. 1997. Asymmetric information in a competitive market game: Reexamining the implications of rational expectations. Working Paper. Ohio State University.

Kyle, S. A. 1985. Continuous auction and insider trading. Econometrica 53: 1315-1335. . 1989. Information speculation with imperfect competition. Review of Economic Studies 56: 317-355.

Lakonishok, J., and I. Lee. 2001. Are insider traders informative? Review of Financial Studies 14: 79-111.

Lintner, J. 1965. The valuation of risk assets and the selection of risky investment in stock portfolios and capital budgets. The Review of Economics and Statistics 47: 13-37.

1969. The aggregation of investor's diverse judgments and preferences in purely competitive security markets. Journal of Financial and Quantitative Analysis 4: $347-400$ 
Sartono-The Existence of Equilibrium Asset Price under Diverse Information

Milgrom, R. P. 1981. Rational expectation, information acquisition and competitive bidding. Econometrica 49: 921-943.

Milgrom, R. P., and N. Stokey. 1982. Information, trade and common knowledge. Journal of Economic Theory 26: 17-27.

Miller, M. E. 1977. Risk, uncertainty, and divergence of opinion. Journal of Finance 32: 1151-1169.

Nöldeke, G., and Th. Tröger. 2001. Existence of linear equilibria in the Kyle model with multiple informed traders. Discussion Paper. Bonn Graduate School of Economics, University of Bonn, Bonn.

O’Hara, M. 1995. Market Micro Structure Theory. Massachusetts, USA: Blackwell Publisher.

Sartono, R. A. 2005. Trading behavior and asset pricing under heterogeneous expectations. Gadjah Mada International Journal of Business 7 (1): 15-39.

Schredelseker, K. 1980. Unequally distributed information and stock market theory. Wuppartel 50: 1-19.

. 1982. Towards an equilibrium degree of market efficiency. Working Paper: 1043-1061. University of Innsbruck, Innsbruck, Austria.

. 1997. On the value of information in financial decisions: A simulation approach. Working Paper. University of Innsbruck, Innsbruck, Austria.

Sharpe, F. W. 1964. Capital asset prices: A theory ofmarket equilibrium under conditions of risk. Journal of Finance 19: 425-442.

. 1972. Risk, market sensitivity, and diversification. Financial Anahighsts Journal(January/February): 74-79.

Spiegel, M., and A. Subrahmanyam. 1992. Informed speculation and hedging in a noncompetitive securities market. Review of Financial Studies 5: 307-329.

Verrecchia, E. R. 1982. Information acquisition in a noisy rational expectation economy. Econometrica 50: 1415-1430.

Williams, T. J. 1977. Capital asset prices with heterogeneous beliefs. Journal of Financial Economics 5: 219-239. 